Review

\title{
SARS-CoV-2-Induced Damage on the Cardiovascular System: Molecular Mechanisms
}

\author{
Mel·lina Pinsach-Abuin and Ramon Brugada Terradellas \\ Cardiovascular Genetics Center, Institut d'Investigació Biomèdica de Girona, Spain
}

\author{
Article history \\ Received: 02-03-2021 \\ Revised: 05-05-2021 \\ Accepted: 10-05-2021 \\ Corresponding Author: \\ Ramon Brugada Terradellas \\ Cardiovascular Genetics \\ Center, Institut d'Investigació \\ Biomèdica de Girona, Spain \\ Email: rbrugada@idibgi.org
}

\begin{abstract}
Since its emergence in late December 2019, the severe acute respiratory syndrome coronavirus 2 (SARS-CoV-2) - the causative agent of coronavirus disease 2019 (COVID-19) - has spread rapidly world-wide, becoming a global pandemic in March 2020 that is still active. In addition to the severe pulmonary damage, clinical studies have reported that COVID-19 is associated with the development of cardiovascular alterations such as myocardial injury, particularly in its most severe manifestations. At the same time, pre-existing cardiovascular conditions in COVID-19 cases have been related to an increased risk of adverse outcomes. To date, several mechanisms have been described to participate in the development of cardiovascular damage related to COVID-19, including direct SARS-CoV-2 infection of the cardiovascular system, Angiotensin-Converting Enzyme 2 (ACE2) downregulation, cytokine storm, coagulation abnormalities, hypoxia and drug-induced cardiotoxicity. However, the large amount of information gathered so far makes it difficult to keep up with this new pandemic. In the present review, we provide a clear insight of the extensive literature available and summarize the current understanding of COVID-19-related mechanisms behind SARS-CoV-2-induced damage to the cardiovascular system.
\end{abstract}

Keywords: SARS-CoV-2 Infection, COVID-19, ACE2, Cytokine Storm, Myocardial Injury

\section{Introduction}

Coronavirus disease 2019 (COVID-19) is a novel infectious disease of the human respiratory system caused by the Severe Acute Respiratory Syndrome Coronavirus 2 (SARS-CoV-2) (Wu et al., 2020a; Zhou et al., 2020; Zhu et al., 2020). Coronaviruses are enveloped RNA particles that normally cause mild to moderate respiratory illnesses, such as the common cold. However, some coronaviruses may lead to severe and fatal respiratory infections. SARS-CoV-2 is the newest member of the $\beta$-coronavirus family like the two previous coronaviruses that became respiratory-disease epidemics, mainly occurring in China and Saudi Arabia (Wu et al., 2020b; Zhou et al., 2020; Zhu et al., 2020). These include the SARS-CoV, the causal agent of SARS and the Middle East Respiratory Syndrome (MERS)-CoV, the causal agent of MERS. Since its emergence in Wuhan province in China in late December 2019 (Zhu et al., 2020), SARS-CoV-2 has spread rapidly worldwide resulting in over 86 million confirmed COVID-19 cases with more than 1.8 million deaths as of January 7, 2021 (WHO, 2021).
SARS-CoV-2 is mainly transmitted human-to-human by inhalation of respiratory droplets or aerosols spread by coughing or sneezing from an infected individual. COVID-19 has a mean incubation period of 5.2 days, with an inferred infectiousness profile starting from 12.3 days (95\% CI, 5.9-17.0 days) before symptom onset and peaking at symptom onset (95\% CI, -0.9-0.9 days) (He et al., 2020). The primary symptoms of COVID-19 are fever, dry cough, fatigue and dyspnea. It generally ranges from asymptomatic to mild disease in $80 \%$ of infected cases; although approximately $15 \%$ of cases progress to severe COVID-19 and about 5\% eventually become critically ill (Huang et al., 2020). Although the probability to develop severe complications and death in COVID-19 is higher in the elderly and patients with pre-existing conditions - such as hypertension, cardiovascular disease, diabetes and obesity- (Li et al., 2020), several cases of young and healthy individuals developing acute symptoms have been notified (WHO, 2021). Respiratory complications, such as viral pneumonia and Acute Respiratory Distress Syndrome (ARDS) are the dominant clinical manifestation in severe COVID-19 cases and the main 
cause of death (Polidoro et al., 2020). Apart from respiratory symptoms, early clinical studies describe that about 20-25\% of COVID-19 patients also develop cardiac complications -such as myocarditis, arrhythmias, thromboembolic events and heart failure-, even in the absence of previous cardiovascular conditions (Guzik et al., 2020; Huang et al., 2020). In fact, cardiac damage, as reflected by high troponin levels in the blood, is a common feature observed within hospitalized COVID-19 cases and represents a risk factor for mortality (Zou et al., 2020). Moreover, clinical studies conducted to date have identified that, although a proportion of COVID-19 patients develop cardiac complications, the presence of a pre-existing Cardiovascular Disease (CVD) is a highly prevalent comorbidity among patients with COVID-19, which has been associated with poor prognosis and high mortality rate (Huang et al., 2020; F. Zhou et al., 2020).

In this review we summarize the relationship between SARS-CoV-2 infection and cardiac complications and discuss possible mechanisms underlying SARS-CoV-2induced damage to the cardiovascular system. It is important to highlight that given the novelty of COVID-19, this review contains information based on preliminary research that needs to be interpreted cautiously.

\section{Search Methods}

To write the present review, we gathered from PubMed and Google all research and review articles, bulletins from governmental and health organizations and expert reports published since the emergence of the COVID-19 pandemic. We searched for "SARS-CoV-2", "COVID-19", "ACE2" and "cytokine storm" in combination with "cardiovascular", "myocardial injury" and "heart failure". We also examined relevant references for previous studies about the two other $\beta$-coronaviruses causing respiratory-disease epidemics (SARS-CoV and MERS-CoV).

\section{SARS-CoV-2 Pathogenesis}

SARS-CoV-2 is a spherical particle delineated by a lipid bilayer where the structural Membrane (M), Envelope (E) and Spike (S) proteins are anchored (Jaimes et al., 2020; Masters, 2006) (Fig. 1a). SARS-CoV-2 genome is a positive-sense single-stranded RNA molecule (ssRNA) surrounded by the nucleocapsid $(\mathrm{N})$ proteins, that shares 96.2 and $79.6 \%$ sequence identity with bat coronavirus RaTG13 and SARS-CoV, respectively (F. Wu et al., 2020a; P. Zhou et al., 2020). Given the genetic similarity between SARS-CoV and SARS-CoV-2, the two viruses share many biological features. Both viruses infect human cells through the binding of the $S$ protein to the human Angiotensin-Converting Enzyme 2 (ACE2) receptor on the surface of the host cell (Gallagher and Buchmeier, 2001; Yan et al., 2020). The $\mathrm{S}$ protein comprises two functional domains (S1 and S2) (Fig. 1a and c). The S1 domain forms the "head" of the protein and is responsible for ACE2 receptor binding. The S2 is a transmembrane domain and mediates the fusion of the viral and host cell membranes, a key point for virus infection (Gallagher and Buchmeier, 2001; Yan et al., 2020).

Upon binding to ACE2, the viral S protein is cleaved at the S2 domain by the Transmembrane Protease Serine 2 (TMPRSS2), in a process known as S protein priming. S2 cleavage allows $S$ protein activation, fusion of viral and host cell membranes and direct entry of the viral RNA into the cytoplasm (Hoffmann et al., 2020) (Fig. 1b). Alternatively, viral infection can occur through the endocytic pathway, where the ACE2-virus complex is translocated into the host cell through endosomes (Fig. 1b). In this case, $\mathrm{S}$ protein is cleaved at the $\mathrm{S} 2$ domain by the endosomal cysteine proteases cathepsin $\mathrm{B}$ and cathepsin $\mathrm{L}(\mathrm{CTSB} / \mathrm{L})$ and the viral RNA is released into the cytoplasm after fusion of viral and endosomal membranes (Hoffmann et al., 2020). Once the viral genomic RNA is released into the cytoplasm, it is translated by host cell ribosomes into viral proteins required for viral replication. Then, the viral genome is replicated and the four structural proteins (, E, M and $\mathrm{N}$ ) are translated through the endoplasmic reticulum and Golgi complex of the host cell. Finally, the genomic RNA and the structural proteins are assembled into new viral particles that are released through exocytosis (Fig. 1b) (Du et al., 2009; Hoffmann et al., 2020).

Despite sharing the same infectious mechanism, the $\mathrm{S}$ protein of SARS-CoV-2 contains two distinctive features that are not present in the $\mathrm{S}$ protein of SARS-CoV (Fig. 1c). First, the S protein of SARS-CoV-2 has acquired mutations in five of the six residues critical for ACE2 binding, which increases 10- to 20-fold the binding affinity of SARS-CoV$2 \mathrm{~S}$ protein to ACE2 compared to the $\mathrm{S}$ protein of SARSCoV (Gupta et al., 2020; Wrapp et al., 2020). This increase in binding affinity is thought to increase SARS-CoV-2 transmissibility and severity of COVID-19. Second, the S protein of SARS-CoV-2 contains a furin polybasic cleavage site between $\mathrm{S} 1$ and $\mathrm{S} 1(\mathrm{~S} 1 / \mathrm{S} 2)$ that is not present in the $\mathrm{S}$ protein of SARS-CoV (Fig. 1c). Furin-mediated cleavage generates a polybasic site that has been recently demonstrated to bind to Neutrophilin 1 (NRP1), a member of the neurophilin family of cell surface receptors involved in essential cellular signaling cascades (Guo and Vander Kooi, 2015). This novel furin site enhances SARS-CoV-2 infectivity and broadens the ability of SARS-CoV-2 to infect multiple organs, including the heart (Cantuti-Castelvetri et al., 2020; Daly et al., 2020). Nevertheless, studies of SARS-CoV-2 entry into host cells conducted to date have mainly focused on ACE2 and there is little knowledge about the virus and host mechanisms that determine cellular entry of SARS-CoV-2. 


\section{a Structure of SARS-CoV-2}

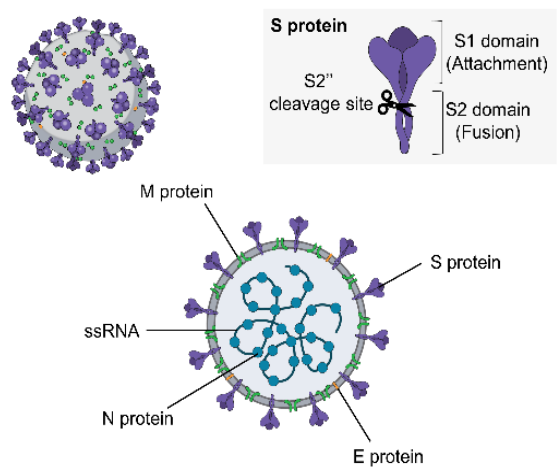

b Life cycle of SARS-CoV-2

(1) Binding and direct viral entry

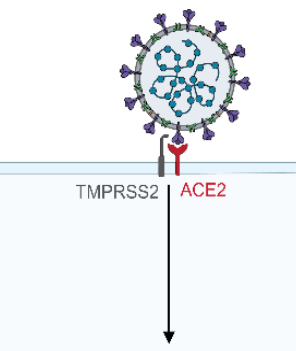

(2) Viral RNA release

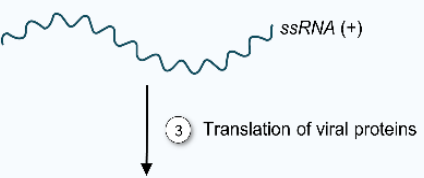

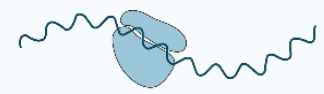

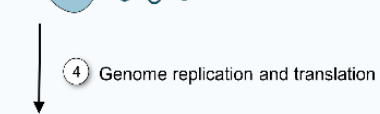

Cytoplasm
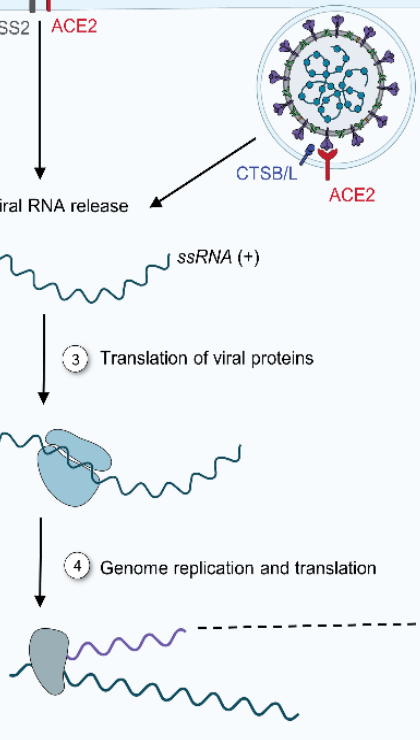

\section{Structure of SARS-CoV-2 and SARS-CoV S protein}

SARS-CoV-2 S protein
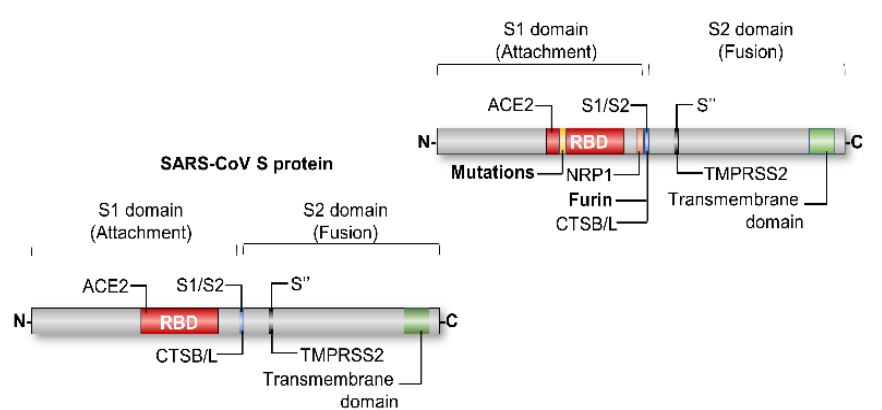

(16) Binding and viral entry through endocytosis
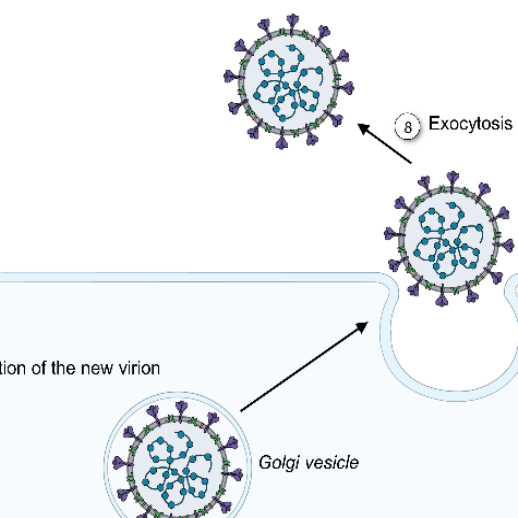

6) Combinaition of structural proteins with nucleocapsid

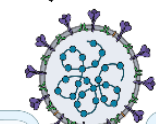

Elements that will be ensembled in the new virion
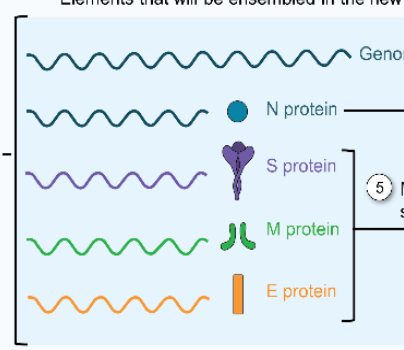

\section{m.}
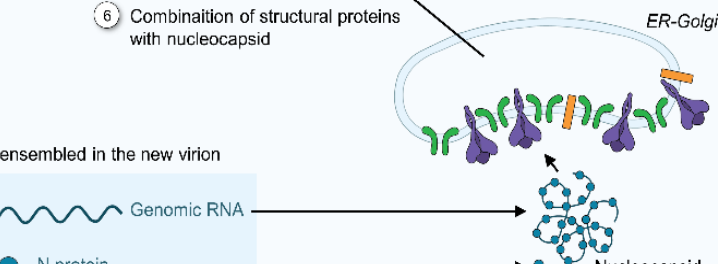

Nucleocapsid

Fig. 1: SARS-CoV-2 structure and pathogenesis (a) The viral positive-sense single-stranded RNA (ssRNA) genome is bound to nucleocapsid $(\mathrm{N})$ proteins and wrapped inside a spherical lipid bilayer, where the structural spike (S), envelope (E) and membrane (M) proteins are anchored. (b) SARS-CoV-2 S protein binds to ACE2 receptor, allowing viral entry into host cell either by direct fusion with the host cell membrane (1a) or via endocytosis with later viral release from the endocytic vesicle to the cytoplasm (1b). Positive ssRNA is released (2), partially translated into SARS-CoV-2 polymerase protein by host cell ribosomes (3). SARS-CoV-2 genome is then replicated and structural SARS-CoV-2 proteins (S, M, E and N) are synthesized (4). Structural proteins S, M and E are taken to the host cell endoplasmic reticulum (ER) membrane (5) and later combined with $\mathrm{N}$ protein (6). The complex is processed in the Golgi and all elements are incorporated into a new virion (7) that is secreted through exocytosis (8). (c) SARS-CoV and SARS-CoV-2 S proteins share the same structure with the S1 domain, responsible for ACE2 binding mediated by the receptor-binding domain (RBD); and the S2 domain, responsible for membrane fusion. However, compared to SARS-CoV, the S protein of SARS-CoV-2 has two remarkable features. On one hand, five of the six residues within the S1 RBD that are crucial for ACE2 binding are mutated, which increases SARS-CoV-2 binding affinity to ACE2. On the other hand, SARS-CoV-2 shows a novel furin cleavage site at the S1/S2 boundary that increases infectivity and the ability to infect multiple organs 


\section{SARS-CoV-2 and the Cardiovascular System}

Coronaviruses are known for their impact on the respiratory tract. However, SARS-CoV-2, the most recent coronavirus also presents a high tropism for the cardiovascular system. In fact, based on all the information gathered so far, it has been observed that about $20-25 \%$ of COVID-19 patients develop cardiovascular complications such as myocarditis, arrhythmias, myocardial injury and thromboembolism (Guzik et al., 2020; Huang et al., 2020; Nishiga et al., 2020) (Fig. 2). Although the underlying mechanisms are not well understood, it has been postulated that myocardial injury may be the result from either direct or indirect mechanisms discussed in the sections below.

\section{Potential Mechanisms Underlying Cardiovascular Dysfunction in COVID-19 Direct Myocardial Infection by SARS-CoV-2}

The ability of SARS-CoV-2 to infect cardiomyocytes has been demonstrated in vitro using human induced pluripotent stem cells-derived cardiomyocytes (hiPS-CMs), where SARS-CoV-2 infection led to sarcomeric structural disruptions affecting the contractile machinery of the myocardium and suspension of cell beating (Bojkova et al., 2020). Moreover, numerous studies have also presented in vivo histological evidence of direct viral infection in the heart. An autopsy case series of 27 patients revealed that, although the highest concentration of SARS-CoV-2 genomic RNA was found in the lungs; the heart, kidney and liver also showed substantial amounts of viral RNA (Puelles et al., 2020). In another autopsy analysis involving 39 patients with COVID-19, a high viral load (above 1000 copies) was detected in the myocardium of $41 \%$ of the patients (Lindner et al., 2020).

As previously mentioned, upon SARS-CoV-2 binding to ACE2, viral entry into the host cell can be mediated by either TMPRSS2 or CTSB/L priming of S protein (Fig. 1b and c). According to the latest version of RNA-sequencing data from the Genotype-Tissue Expression (GTEx) project, ACE2 and CTSB/L are highly expressed in the heart and coronary arteries whereas TMPRSS2 expression is almost undetectable (GTEx Portal, 2020). Consistent with GTEx results, single-cell RNA-sequencing revealed that ACE2 and CTSB/L are highly expressed in cardiomyocytes, while TMPRSS2 is not expressed (Litviňuková et al., 2020). Based on these observations, a conceivable hypothesis is that $\mathrm{S}$ protein priming by CTSB/L and the subsequent activation of the endocytic pathway could mediate SARS-CoV-2 infection of cardiomyocytes. Alternatively, SARS-CoV-2 infection could also be explained by the novel furin cleavage site. As described above, furin-mediated cleavage generates a polybasic site that is recognized and bound by NRP1 protein, a broadly distributed cell surface receptor also expressed in cardiomyocytes (GTEx Portal, 2020).

\section{ACE2 Downregulation}

SARS-CoV-2 infection is mediated by ACE2, an important member of the renin-angiotensin-aldosterone system (RAAS) involved in blood pressure control, sodium reabsorption, inflammation and fibrosis (Vaduganathan et al., 2020) (Fig. 2, middle). In the classic RAAS, angiotensinogen is cleaved by the enzyme renin to form the inactive angiotensin (Ang) I, which is then cleaved by ACE to generate the physiologically active Ang II. Among other functions, Ang II promotes the release of pro-inflammatory cytokines such as interleukin (IL)-6, IL-1 $\beta$ and Tumor Necrosis Factor (TNF)- $\alpha$. These adverse pro-inflammatory properties of Ang II are counteracted by ACE2 through the degradation of Ang II to the protective Ang 1-7 (Ingraham et al., 2020).

ACE2 is expressed in many organs, including the heart (GTEx Portal, 2020; Litviňuková et al., 2020). Several studies have shown that SARS-CoV-2 infection downregulates ACE2 expression on infected cells, thereby shifting RAAS toward the pro-inflammatory ACE/Ang II axis (Banu et al., 2020). Overproduction of Ang II has been linked to cardiac diseases such as heart failure and atrial fibrillation (Ingraham et al., 2020. ACE2 knockout mice shown abnormal heart function and increased Ang II levels, leading to severe cardiac contractility defects, myocardial hypertrophy and heart failure (Crackower et al., 2002; Oudit et al., 2007; Zhong et al., 2010). In the context of COVID-19, early studies found a progressive increase in Ang II and IL-6 levels among COVID-19 hospitalized patients, with the highest levels observed among non-survivors (Miesbach, 2020; Wu et al., 2020b). Ang II levels have additionally been shown to be elevated in several conditions such as hypertension, diabetes mellitus and CVD. The basal inflammation present in patients with these pre-existing conditions could exacerbate SARS-CoV-2 inflammatory response, activating the so-called cytokine storm (explained in the section below) ending in multi-organ failure. Therefore, inherent RAAS-ACE2 dysregulation in conditions such as hypertension, diabetes and CVD could explain why these comorbidities are frequently observed in severe COVID-19 cases.

\section{Cytokine Storm}

SARS-CoV-2 entry into host cells activates the immune system and the release of pro-inflammatory cytokines such as IL-6, IL-1 $\beta$ TNF- $\alpha$ that, among other functions, activate immune cells such as macrophages and T lymphocytes to fight the virus (Moore and June, 2020; Zhang et al., 2020). Upon SARS-CoV-2 infection in the respiratory system, approximately $80 \%$ of patients present a proper antiviral immune response successfully eliminating 
the virus (Polidoro et al., 2020). However, some COVID-19 patients develop an exaggerated immune response with massive release of pro-inflammatory cytokines (Moore and June, 2020; Zhang et al., 2020). Increased levels of pro-inflammatory cytokines have been associated to COVID-19 severity and worse prognosis. Several clinical studies reported that deceased COVID-19 patients present significantly higher levels of pro-inflammatory cytokines compared to patients who recover from the disease (Moore and June, 2020; Zhang et al., 2020).

Although triggered by local infection, the magnified immune response in the lungs further increases lung inflammation, leading to ARDS. This increase in lung inflammation also results in a loop of systemic inflammation characterized by an overproduction of pro-inflammatory cytokines, also known as cytokine storm, that activate dysfunctional remodeling pathways in multiple organs, including the heart (Huang et al., 2020; Xu et al., 2020). In fact, it has been described that increased levels of pro-inflammatory cytokines TNF- $\beta$, IL- $1 \alpha$ and IL- 6 in the heart may contribute to the development of myocardial injury (Bozkurt et al., 1998; Hasdai et al., 1996; Matsumori et al., 1994; Palmer et al., 1995). Additionally, these pro-inflammatory cytokines could lead to electrical disturbances in the heart, as they have been shown to negatively regulate the expression of important proteins for both cardiac excitation-contraction and cell-cell coupling (Pinto and Boyden, 1999). Therefore, it is not surprising that multiple clinical studies now report that severely COVID-19 infected patients show a significant arrhythmogenic burden including heart palpitations and tachycardia (Driggin et al., 2020; Lang et al., 2020; Nishiga et al., 2020).

In addition to the direct inflammatory damage, it has also been proposed that the cytokine storm could contribute to lymphopenia (abnormally low levels of lymphocytes in the blood) observed in a significant proportion of severe COVID-19 cases (Fathi and Rezaei, 2020). Lymphopenia has been previously associated with cardiovascular diseases and it has been recommended to use the relative lymphocyte concentration as a prognostic marker in patients with acute and chronic coronary artery disease (Ommen et al., 1998).

\section{Coagulation Abnormalities and Thrombotic Events}

It has been shown that SARS-CoV-2 infection, RAAS alterations and the cytokine storm simultaneously trigger the production of the coagulation factors thrombin and fibrinogen that increase blood coagulability, a major risk factor for atherothrombotic cardiovascular events (Hiraiwa and Van Eeden, 2014). To counteract thrombi formation, blood clots are regularly degraded by specific enzymes, which leads to an increase in fibrin degradation products such as D-dimer (Bikdeli et al., 2020). Recent reports in COVID-19 patients also highlight the presence of aberrant coagulation products such as D-dimer, whose elevated levels were correlated with COVID-19 disease severity (Bikdeli et al., 2020; Connors and Levy, 2020; Tang et al., 2020; F. Zhou et al., 2020). This increase in coagulation parameters in COVID-19 patients suggests the presence of a hypercoagulable state that can result in thromboembolic events. A prospective autopsy study revealed that 7 of 12 patients who died of COVID-19 presented deep vein thrombosis, even when venous thromboembolism was not suspected prior to death (Wichmann et al., 2020). Interestingly, another study with 183 COVID-19 patients found that $71 \%$ of those who died met the criteria for disseminated intravascular coagulation from the International Society on Thrombosis and Haemostasis (Taylor et al., 2001), compared with only $0.6 \%$ of COVID-19 patients that survived (Tang et al., 2020). Coagulation abnormalities could also affect cardiac blood flow or destabilize existing coronary artery plaques, known triggers of myocardial ischemia (Libby et al., 2018). Additionally, the acute immobilization of critically ill patients in intensive care unit could also contribute to the hypercoagulable state observed in COVID-19 patients.

\section{Hypoxia}

Inflammation and lung injury can also lead to hypoxemia, or low circulating oxygen levels. As described earlier, the acute immune response in the lungs induces inflammatory damage to endothelial alveoluscapillary membrane, increasing pulmonary permeability and edema that leads to ARDS (Xu et al., 2020). Fluid entry into the airspaces impairs gaseous exchanges between the respiratory and vascular systems, leading to dyspnea. Dyspnea has been reported in over $50 \%$ of severe COVID-19 cases, being more common in deceased COVID-19 patients compared to those who recovered from the disease (Allali et al., 2020; Chen et al., 2020). In the context of the cardiovascular system, hypoxemia causes reduced energy supply to cardiomyocytes, which could promote the development of myocardial injury, including arrhythmia and shock (Allali et al., 2020; Wang et al., 2020).

\section{Drug-Induced Cardiovascular Toxicity}

Other than the aforementioned mechanisms for induced effects of COVID-19 in the cardiovascular system, the potential drug-disease interactions in patients with COVID-19 have become a matter of debate. On one hand, some of the potential anti-SARS-CoV-2 drugs used to treat patients with COVID-19 have been described to induce cardiovascular toxicity or interact with other cardiovascular medications (Sanders et al., 2020) (Table 1). On the other hand, it is still unknown whether usage of common cardiovascular drugs such as ACE inhibitors or Ang II Receptor Blockers (ARBs) 
influence susceptibility and/or severity of COVID-19 (Vaduganathan et al., 2020).

\section{Underlying Cardiovascular Comorbidities}

COVID-19 has been strongly associated with CVD, similar to previous coronavirus respiratory disease outbreaks. Clinical studies conducted so far have identified that the presence of pre-existing CVD or its associated risk factors (such as hypertension and diabetes mellitus) are highly prevalent comorbidities among patients with COVID-19, especially in critically ill patients (Nishiga et al., 2020). A meta-analysis of 1,527 patients with COVID-19 reported that $17.1 \%$ had a history of hypertension, $9.7 \%$ of diabetes and $16.4 \%$ of CVD (Li et al., 2020). A significantly larger report from the Chinese Center for Disease Control and Prevention described clinical comorbidities in 44,672 patients with COVID-19. In the study, the overall case fatality rate was $2.3 \%$ and it was significantly higher in patients with CVD (10.5\%) (Wu and McGoogan, 2020).

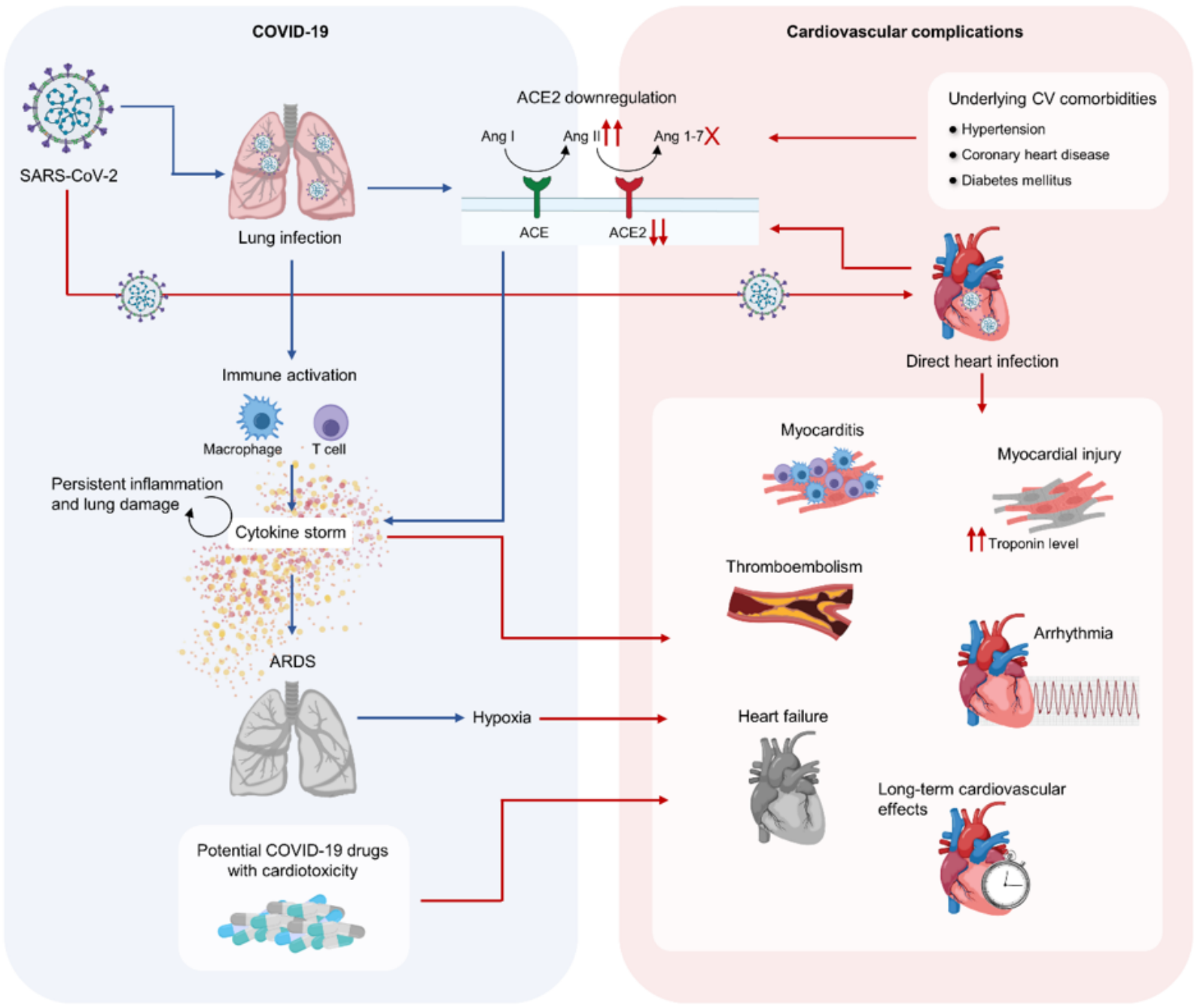

Fig. 2: Possible mechanisms of cardiovascular injury due to COVID-19 SARS-CoV-2 primarily infects the respiratory system (left panel). SARS-CoV-2 infection downregulates ACE2 that, in combination with immune cell over-activation and massive release of pro-inflammatory cytokines (cytokine storm), lead to lung failure and Acute Respiratory Distress Syndrome (ARDS) in severe COVID-19 cases. In the cardiovascular system (right panel), cardiac complications can be triggered by direct SARS-CoV-2 infection or by indirect mechanisms during COVID-19. Immune over-activity can precipitate blood clot formation leading to thromboembolism. Also, acute inflammation can promote the development of myocardial injury including myocarditis, arrhythmia and heart failure. ARDS-derived hypoxia can also lead to cardiac injury due to the reduced energy supply to cardiomyocytes in patients with this condition. Moreover, some medications that have been proposed as treatments for COVID-19 have cardiovascular toxicity. Finally, pre-existing cardiovascular comorbidities such as hypertension and coronary heart disease may also play an important pathophysiological role in the development of cardiovascular complications during COVID-19 
Table 1: Mechanisms and adverse cardiovascular effects of some drugs used to treat COVID-19

\begin{tabular}{|c|c|c|}
\hline Drug & Mechanism of action & CV toxicity \\
\hline 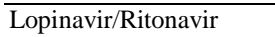 & Inhibits 3-chymotrypsin-likeprotease & QT interval prolongation and atrioventricular block \\
\hline Remdesivir & Inhibit viral RNA replication & Unknown, but limited clinical data \\
\hline Favipiravir & Inhibit viral RNA replication & Prolonged QT, but not common \\
\hline Chloroquine & Block virus entry via endocytosis & $\begin{array}{l}\text { QT interval prolongation, myocardial } \\
\text { toxicity, conduction disorders, torsade des pointes }\end{array}$ \\
\hline Hydroxychloroquine & Block virus entry via endocytosis & $\begin{array}{l}\text { QT interval prolongation, myocardial } \\
\text { toxicity, conduction disorders, torsade des pointes }\end{array}$ \\
\hline Convalescent plasma & Neutralizes immunoglobulins targeting SARS-CoV-2 & Unknown, but limited clinical data \\
\hline Piperacillin-Tazobactam & Inhibits bacterial $\beta$-lactamase activity & Torsade des pointes \\
\hline Ceftriaxone & Inhibits bacterial $\beta$-lactamase activity & Cardiac arrest \\
\hline Levofloxacin & Inhibits bacterial DNA replication & QT prolongation and torsade des pointes \\
\hline Azithromycin & Inhibits bacterial growth. It has additional immunomodulatory effects & QT prolongation and torsade des pointes \\
\hline
\end{tabular}

In addition to being widely prevalent, CVD can also be triggered by SARS-CoV-2 infection in patients with no prior history of heart disease. Indeed, several studies of hospitalized COVID-19 patients without previous history of cardiovascular disease observed that patients with raised cardiac injury biomarkers, such as troponin $\mathrm{TnI}$ and TnT, had significantly higher mortality rates $(\sim 50-$ $60 \%)$ compared to those with normal levels ( 4.5-9\%) (Guo et al., 2020; Shi et al., 2020).

\section{Potential Long-Term Cardiac Consequences}

COVID-19 is a very recent pandemic and the long-term cardiac outcome of patients who recover from this condition remain to be seen. While the immediate cardiac damage has already been manifested by severe COVID-19 patients, the long-term effects on the cardiovascular system remain currently unknown. Due to the considerable similarity between SARS-CoV-2 and SARS-CoV, some important insights can be glanced from previous experience with SARS. For example, in a 12-years follow-up study, about $40 \%$ of patients who had recovered from SARS presented cardiovascular abnormalities (Wu et al., 2017). Therefore, patients who recover from severe COVID-19 could be at higher risk of developing CVD, reinforcing the need for additional studies to gain insight in the molecular mechanisms leading to cardiac injury in COVID-19 patients. A better understanding in COVID-19 pathophysiology would also promote the development of screening and therapeutic interventions to prevent COVID-19-associated cardiac injury in the future.

\section{Conclusion}

SARS-CoV-2, the newest member of the $\beta$-coronavirus family, is a highly transmissible virus that has caused a global pandemic with more than 1.8 million deaths as of January 7 , 2021. Although COVID-19 is primarily a respiratory illness and ARDS is the main clinical complication in severe COVID-19 cases, approximately $20-25 \%$ of patients also develop cardiac complications such as myocardial injury, arrhythmia, cardiac arrest, cardiomyopathy, heart failure, or cardiogenic shock. In addition, a high prevalence of pre-existing CVD and its associated risk factors have been observed in COVID-19 patients, which predispose to an increased risk of severe COVID-19 disease and mortality. Even though our knowledge about COVID19 has expanded rapidly, there are several aspects regarding the pathophysiology of the disease that are not completely understood. Limited results presented so far suggest that ACE2 and inflammation -either local or systemic- play a crucial role in prompting and potentiating existing and new cardiac functional abnormalities. In summary, we suggest that future studies should focus on the understanding of the molecular mechanisms that drive COVID-19 related cardiac complications. Also, it would be interesting to examine the role of CVD-susceptibility variants in COVID-19-induced cardiovascular manifestations.

\section{Acknowledgement}

We acknowledge S. Pagans, M. Verges and B. del Olmo for their contribution in reviewing the original draft.

\section{Funding Information}

This work was supported by the Biomedical Research Institute from Girona (IDIBGI), University Hospital Dr. Josep Trueta from Girona and Obra Social La Caixa. M.P.A. is also supported by Fondo Supera COVID-19 from Banco de Santander. The funders had no role in the design, preparation, review or approval of the manuscript.

\section{Author contributions}

Mel-lina Pinsach-Abuin: Has reviewed the relevant articles on SARS-CoV-2 published to date with the aim to provide a simplified overview of the molecular mechanisms underlying cardiovascular involvement in COVID-19. She has contributed to the conceptualization, writing the original draft, reviewing and editing.

Ramon Brugada Terradellas: Has contributed to writing the original draft, reviewing and editing. 


\section{Ethics}

This article is original and contains unpublished material. The corresponding author confirms that all of the other authors have read and approved the manuscript and there are no ethical issues involved.

\section{References}

Allali, G., Marti, C., Grosgurin, O., Morélot-Panzini, C., Similowski, T., \& Adler, D. (2020). Dyspnea: The vanished warning symptom of COVID-19 pneumonia. Journal of Medical Virology, 92(11), 2272-2273. doi.org/10.1002/jmv.26172

Banu, N., Panikar, S. S., Leal, L. R., \& Leal, A. R. (2020). Protective role of ACE2 and its downregulation in SARS-CoV-2 infection leading to Macrophage Activation Syndrome: Therapeutic implications. In Life Sciences (Vol. 256). Elsevier Inc. doi.org/10.1016/j.lfs.2020.117905

Bikdeli, B., Madhavan, M. V., Jimenez, D., Chuich, T., Dreyfus, I., Driggin, E., ... \& Lip, G. Y. (2020). COVID-19 and thrombotic or thromboembolic disease: implications for prevention, antithrombotic therapy and follow-up: JACC state-of-the-art review. Journal of the American college of cardiology, 75(23), 2950-2973. doi.org/10.1016/j.jacc.2020.04.031

Bojkova, D., Wagner, J. U. G., Shumliakivska, M., Aslan, G. S., Saleem, U., Hansen, A., Luxán, G., Günther, S., Pham, M. D., Krishnan, J., Harter, P. N., Ermel, U. H., Frangakis, A. S., Milting, H., Zeiher, A. M., Klingel, K., Cinatl, J., Dendorfer, A., Eschenhagen, T., ... Dimmeler, S. (2020). SARS-CoV-2 infects and induces cytotoxic effects in human cardiomyocytes. Cardiovascular Research. doi.org/10.1093/cvr/cvaa267

Bozkurt, B., Kribbs, S. B., Clubb, F. J., Michael, L. H., Didenko, V. V., Hornsby, P. J., Seta, Y., Oral, H., Spinale, F. G., \& Mann, D. L. (1998). Pathophysiologically relevant concentrations of tumor necrosis factor- $\alpha$ promote progressive left ventricular dysfunction and remodeling in rats. Circulation, 97(14), 1382-1391. doi.org/10.1161/01.CIR.97.14.1382

Cantuti-Castelvetri, L., Ojha, R., Pedro, L. D., Djannatian, M., Franz, J., Kuivanen, S., van der Meer, F., Kallio, K., Kaya, T., Anastasina, M., Smura, T., Levanov, L., Szirovicza, L., Tobi, A., Kallio-Kokko, H., Österlund, P., Joensuu, M., Meunier, F. A., Butcher, S. J., ... Simons, M. (2020). Neuropilin-1 facilitates SARS-CoV-2 cell entry and infectivity. Science (New York, N.Y.). doi.org/10.1126/science.abd2985
Chen, T., Wu, D., Chen, H., Yan, W., Yang, D., Chen, G., Ma, K., Xu, D., Yu, H., Wang, H., Wang, T., Guo, W., Chen, J., Ding, C., Zhang, X., Huang, J., Han, M., Li, S., Luo, X., ... Ning, Q. (2020). Clinical characteristics of 113 deceased patients with coronavirus disease 2019: Retrospective study. The BMJ, 368. doi.org/10.1136/bmj.m1091

Connors, J. M., \& Levy, J. H. (2020). Thromboinflammation and the hypercoagulability of COVID-19. In Journal of Thrombosis and Haemostasis (Vol. 18, Issue 7, pp. 1559-1561). Blackwell Publishing Ltd. doi.org/10.1111/jth.14849

Crackower, M. A., Sarao, R., Oliveira-dos-Santos, A. J., Da Costa, J., \& Zhang, L. (2002). Angiotensinconverting enzyme 2 is an essential regulator of heart function. Nature, 417(6891), 822-828. doi.org/10.1038/nature00786

Daly, J. L., Simonetti, B., Klein, K., Chen, K.-E., Williamson, M. K., Antón-Plágaro, C., Shoemark, D. K., Simón-Gracia, L., Bauer, M., Hollandi, R., Greber, U. F., Horvath, P., Sessions, R. B., Helenius, A., Hiscox, J. A., Teesalu, T., Matthews, D. A., Davidson, A. D., Collins, B. M., ... Yamauchi, Y. (2020). Neuropilin-1 is a host factor for SARS-CoV-2 infection. Science, 370(6518), eabd3072. doi.org/10.1126/science.abd3072

Driggin, E., Madhavan, M. V., Bikdeli, B., Chuich, T., Laracy, J., Biondi-Zoccai, G., Brown, T. S., Der Nigoghossian, C., Zidar, D. A., Haythe, J., Brodie, D., Beckman, J. A., Kirtane, A. J., Stone, G. W., Krumholz, H. M., \& Parikh, S. A. (2020). Cardiovascular Considerations for Patients, Health Care Workers and Health Systems During the COVID-19 Pandemic. In Journal of the American College of Cardiology (Vol. 75, Issue 18, pp. 2352-2371). Elsevier USA. doi.org/10.1016/j.jacc.2020.03.031

Du, L., He, Y., Zhou, Y., Liu, S., Zheng, B. J., \& Jiang, S. (2009). The spike protein of SARS-CoV - A target for vaccine and therapeutic development. In Nature Reviews Microbiology (Vol. 7, Issue 3, pp. 226-236). Nature Publishing Group. doi.org/10.1038/nrmicro2090

Fathi, N., \& Rezaei, N. (2020). Lymphopenia in COVID-19: Therapeutic opportunities. Cell Biology International, 44(9), 1792-1797. doi.org/10.1002/cbin.11403

Gallagher, T. M., \& Buchmeier, M. J. (2001). Coronavirus spike proteins in viral entry and pathogenesis. Virology, 279(2), 371-374. doi.org/10.1006/viro.2000.0757

GTEx Portal. (2020). https://gtexportal.org/home

Guo, H. F., \& Vander Kooi, C. W. (2015). Neuropilin functions as an essential cell surface receptor. In Journal of Biological Chemistry (Vol. 290, Issue 49, pp. 29120-29126). American Society for Biochemistry and Molecular Biology Inc. doi.org/10.1074/jbc.R115.687327 
Guo, T., Fan, Y., Chen, M., Wu, X., Zhang, L., He, T., Wang, H., Wan, J., Wang, X., \& Lu, Z. (2020). Cardiovascular Implications of Fatal Outcomes of Patients with Coronavirus Disease 2019 (COVID-19). JAMA Cardiology, 5(7), 811-818. doi.org/10.1001/jamacardio.2020.1017

Gupta, A., Madhavan, M. V., Sehgal, K., Nair, N., Mahajan, S., Sehrawat, T. S., Bikdeli, B., Ahluwalia, N., Ausiello, J. C., Wan, E. Y., Freedberg, D. E., Kirtane, A. J., Parikh, S. A., Maurer, M. S., Nordvig, A. S., Accili, D., Bathon, J. M., Mohan, S., Bauer, K. A., ... Landry, D. W. (2020). Extrapulmonary manifestations of COVID-19. In Nature Medicine (Vol. 26, Issue 7, pp. 1017-1032). Nature Research. doi.org/10.1038/s41591-020-0968-3

Guzik, T. J., Mohiddin, S. A., Dimarco, A., Patel, V., Savvatis, K., Marelli-Berg, F. M., Madhur, M. S., Tomaszewski, M., Maffia, P., D’Acquisto, F., Nicklin, S. A., Marian, A. J., Nosalski, R., Murray, E. C., Guzik, B., Berry, C., Touyz, R. M., Kreutz, R., Dao, W. W., ... McInnes, I. B. (2020). COVID-19 and the cardiovascular system: Implications for risk assessment, diagnosis and treatment options. In Cardiovascular Research (Vol. 116, Issue 10, pp. 1666-1687). Oxford University Press. doi.org/10.1093/cvr/cvaa106

Hasdai, D., Scheinowitz, M., Leibovitz, E., Sclarovsky, S., Eldar, M., \& Barak, V. (1996). Increased serum concentrations of interleukin-1 $\beta$ in patients with coronary artery disease. Heart, 76(1), 24-28. doi.org/10.1136/hrt.76.1.24

He, X., Lau, E. H. Y., Wu, P., Deng, X., Wang, J., Hao, X., Lau, Y. C., Wong, J. Y., Guan, Y., Tan, X., Mo, X., Chen, Y., Liao, B., Chen, W., Hu, F., Zhang, Q., Zhong, M., Wu, Y., Zhao, L., ... Leung, G. M. (2020). Temporal dynamics in viral shedding and transmissibility of COVID-19. Nature Medicine, 26(5), 672-675. doi.org/10.1038/s41591-020-0869-5

Hiraiwa, K., \& van Eeden, S. F. (2014). Nature and Consequences of the Systemic Inflammatory Response Induced by Lung Inflammation. In Lung Inflammation. InTech. doi.org/10.5772/57392

Hoffmann, M., Kleine-Weber, H., Schroeder, S., Krüger, N., Herrler, T., Erichsen, S., Schiergens, T. S., Herrler, G., Wu, N. H., Nitsche, A., Müller, M. A., Drosten, C., \& Pöhlmann, S. (2020). SARS-CoV-2 Cell Entry Depends on ACE2 and TMPRSS2 and Is Blocked by a Clinically Proven Protease Inhibitor. Cell, 181(2), 271-280.e8. doi.org/10.1016/j.cell.2020.02.052

Huang, C., Wang, Y., Li, X., Ren, L., Zhao, J., Hu, Y., Zhang, L., Fan, G., Xu, J., Gu, X., Cheng, Z., Yu, T., Xia, J., Wei, Y., Wu, W., Xie, X., Yin, W., Li, H., Liu, M., ... Cao, B. (2020). Clinical features of patients infected with 2019 novel coronavirus in Wuhan, China. The Lancet, 395(10223), 497-506. doi.org/10.1016/S0140-6736(20)30183-5
Ingraham, N. E., Barakat, A. G., Reilkoff, R., Bezdicek, T., Schacker, T., Chipman, J. G., Tignanelli, C. J., \& Puskarich, M. A. (2020). Understanding the renin-angiotensin-aldosteroneSARS-CoV axis: a comprehensive review. doi.org/10.1183/13993003.00912-2020

Jaimes, J. A. andré, N. M., Chappie, J. S., Millet, J. K., \& Whittaker, G. R. (2020). Phylogenetic Analysis and Structural Modeling of SARS-CoV-2 Spike Protein Reveals an Evolutionary Distinct and Proteolytically Sensitive Activation Loop. Journal of Molecular Biology, 432(10), 3309-3325. doi.org/10.1016/j.jmb.2020.04.009

Lang, J. P., Wang, X., Moura, F. A., Siddiqi, H. K., Morrow, D. A., \& Bohula, E. A. (2020). A current review of COVID-19 for the cardiovascular specialist. In American Heart Journal (Vol. 226, pp. 29-44). Mosby Inc. doi.org/10.1016/j.ahj.2020.04.025

Li, B., Yang, J., Zhao, F., Zhi, L., Wang, X., Liu, L., Bi, Z., \& Zhao, Y. (2020). Prevalence and impact of cardiovascular metabolic diseases on COVID-19 in China. In Clinical Research in Cardiology (Vol. 109, Issue 5, pp. 531-538). Springer. doi.org/10.1007/s00392-020-01626-9

Libby, P., Loscalzo, J., Ridker, P. M., Farkouh, M. E., Hsue, P. Y., Fuster, V., Hasan, A. A., \& Amar, S. (2018). Inflammation, Immunity and Infection in Atherothrombosis: JACC Review Topic of the Week. In Journal of the American College of Cardiology (Vol. 72, Issue 17, pp. 2071-2081). Elsevier USA. doi.org/10.1016/j.jacc.2018.08.1043

Lindner, D., Fitzek, A., Bräuninger, H., Aleshcheva, G., Edler, C., Meissner, K., Scherschel, K., Kirchhof, P., Escher, F., Schultheiss, H. P., Blankenberg, S., Püschel, K., \& Westermann, D. (2020). Association of Cardiac Infection with SARS-CoV-2 in Confirmed COVID-19 Autopsy Cases. JAMA Cardiology. doi.org/10.1001/jamacardio.2020.3551

Litviňuková, M., Talavera-López, C., Maatz, H., Reichart, D., Worth, C. L., Lindberg, E. L., Kanda, M., Polanski, K., Heinig, M., Lee, M., Nadelmann, E. R., Roberts, K., Tuck, L., Fasouli, E. S., DeLaughter, D. M., McDonough, B., Wakimoto, H., Gorham, J. M., Samari, S., ... Teichmann, S. A. (2020). Cells of the adult human heart. Nature, 588(7838), 466-472. doi.org/10.1038/s41586-020-2797-4

Masters, P. S. (2006). The Molecular Biology of Coronaviruses. In Advances in Virus Research (Vol. 65, pp. 193-292). Academic Press. doi.org/10.1016/S0065-3527(06)66005-3

Matsumori, A., Yamada, T., Suzuki, H., Matoba, Y., \& Sasayama, S. (1994). Increased circulating cytokines in patients with myocarditis and cardiomyopathy. British Heart Journal, 72(6), 561566. doi.org/10.1136/hrt.72.6.561 
Miesbach, W. (2020). Pathological Role of Angiotensin II in Severe COVID-19. TH Open, 04(02), e138-e144. doi.org/10.1055/s-0040-1713678

Moore, J. B., \& June, C. H. (2020). Cytokine release syndrome in severe COVID-19. Science, 368(6490). doi.org/10.1016/S2213

Nishiga, M., Wang, D. W., Han, Y., Lewis, D. B., \& Wu, J. C. (2020). COVID-19 and cardiovascular disease: from basic mechanisms to clinical perspectives. In Nature Reviews Cardiology (Vol. 17, Issue 9, pp. 543-558). Nature Research. doi.org/10.1038/s41569-020-0413-9

Ommen, S. R., Hodge, D. O., Rodehefer, R. J., McGregor, C. G. A., Thomson, S. P., \& Gibbons, R. J. (1998). Predictive power of the relative lymphocyte concentration in patients with advanced heart failure. Circulation, 97(1), 19-22. doi.org/10.1161/01.CIR.97.1.19

Oudit, G. Y., Kassiri, Z., Patel, M. P., Chappell, M., Butany, J., Backx, P. H., Tsushima, R. G., Scholey, J. W., Khokha, R., \& Penninger, J. M. (2007). Angiotensin II-mediated oxidative stress and inflammation mediate the age-dependent cardiomyopathy in ACE2 null mice. Cardiovascular Research, 75(1), 29-39. doi.org/10.1016/j.cardiores.2007.04.007

Palmer, J. N., Hartogensis, W. E., Patten, M., Fortuin, F. D., \& Long, C. S. (1995). Interleukin-1 $\beta$ induces cardiac myocyte growth but inhibits cardiac fibroblast proliferation in culture. Journal of Clinical Investigation, 95(6), 2555-2564. doi.org/10.1172/JCI117956

Pinto, J. M. B., \& Boyden, P. A. (1999). Electrical remodeling in ischemia and infarction. In Cardiovascular Research (Vol. 42, Issue 2, pp. 284-297). Oxford Academic. doi.org/10.1016/S0008-6363(99)00013-9

Polidoro, R. B., Hagan, R. S., de Santis Santiago, R., \& Schmidt, N. W. (2020). Overview: Systemic Inflammatory Response Derived From Lung Injury Caused by SARS-CoV-2 Infection Explains Severe Outcomes in COVID-19. In Frontiers in Immunology (Vol. 11, p. 1626). Frontiers Media S.A. doi.org/10.3389/fimmu.2020.01626

Puelles, V. G., Lütgehetmann, M., Lindenmeyer, M. T., Sperhake, J. P., Wong, M. N., Allweiss, L., Chilla, S. Heinemann, A., Wanner, N., Liu, S., Braun, F., Lu, S., Pfefferle, S., Schröder, A. S., Edler, C., Gross, O., Glatzel, M., Wichmann, D., Wiech, T., ... Huber, T. B. (2020). Multiorgan and Renal Tropism of SARSCoV-2. New England Journal of Medicine, 383(6), 590-592. doi.org/10.1056/nejmc2011400
Sanders, J. M., Monogue, M. L., Jodlowski, T. Z., \& Cutrell, J. B. (2020). Pharmacologic Treatments for Coronavirus Disease 2019 (COVID-19): A Review. In JAMA - Journal of the American Medical Association (Vol. 323, Issue 18, pp. 1824-1836). American Medical Association. doi.org/10.1001/jama.2020.6019

Shi, S., Qin, M., Shen, B., Cai, Y., Liu, T., Yang, F., Gong, W., Liu, X., Liang, J., Zhao, Q., Huang, H., Yang, B., \& Huang, C. (2020). Association of Cardiac Injury with Mortality in Hospitalized Patients with COVID-19 in Wuhan, China. JAMA Cardiology, 5(7), 802-810. doi.org/10.1001/jamacardio.2020.0950

Tang, N., Li, D., Wang, X., \& Sun, Z. (2020). Abnormal coagulation parameters are associated with poor prognosis in patients with novel coronavirus pneumonia. Journal of Thrombosis and Haemostasis, 18(4), 844-847. doi.org/10.1111/jth.14768

Taylor, J., Toh, C. H., Hoots, W. K., Wada, H., \& Levi, M. (2001). Towards definition, clinical and laboratory criteria and a scoring system for disseminated intravascular coagulation: On behalf of the scientific subcommittee on Disseminated Intravascular Coagulation (DIC) of the International Society on Thrombosis and Haematostasis (ISTH). In Thrombosis and Haemostasis (Vol. 86, Issue 5, pp. 1327-1330). Schattauer GmbH. doi.org/10.1055/s-0037-1616068

Vaduganathan, M., Vardeny, O., Michel, T., McMurray, J. J. V., Pfeffer, M. A., \& Solomon, S. D. (2020). ReninAngiotensin-Aldosterone System Inhibitors in Patients with Covid-19. New England Journal of Medicine, 382(17), 1653-1659. doi.org/10.1056/nejmsr2005760

Wang, D., Hu, B., Hu, C., Zhu, F., Liu, X., Zhang, J., Wang, B., Xiang, H., Cheng, Z., Xiong, Y., Zhao, Y., Li, Y., Wang, X., \& Peng, Z. (2020). Clinical Characteristics of 138 Hospitalized Patients with 2019 Novel Coronavirus-Infected Pneumonia in Wuhan, China. JAMA - Journal of the American Medical Association, 323(11), 1061-1069. doi.org/10.1001/jama.2020.1585

WHO. (2021). WHO Coronavirus Disease (COVID-19) Dashboard. Retrieved January 7, 2021, from https://covid19.who.int/

Wichmann, D., Sperhake, J. P., Lütgehetmann, M., Steurer, S., Edler, C., Heinemann, A., Heinrich, F., Mushumba, H., Kniep, I., Schröder, A. S., Burdelski, C., de Heer, G., Nierhaus, A., Frings, D., Pfefferle, S., Becker, H., Bredereke-Wiedling, H., de Weerth, A., Paschen, H. R., ... Kluge, S. (2020). Autopsy Findings and Venous Thromboembolism in Patients With COVID-19: A Prospective Cohort Study. Annals of Internal Medicine, 173(4), 268-277. doi.org/10.7326/M20-2003 
Wrapp, D., Wang, N., Corbett, K. S., Goldsmith, J. A. Hsieh, C.-L., Abiona, O., Graham, B. S., \& Mclellan, J. S. (2020). Cryo-EM structure of the 2019-nCoV spike in the prefusion conformation. doi.org/10.1126/science.abb2507

Wu, F., Zhao, S., Yu, B., Chen, Y. M., Wang, W., Song, Z. G., Hu, Y., Tao, Z. W., Tian, J. H., Pei, Y. Y., Yuan, M. L., Zhang, Y. L., Dai, F. H., Liu, Y., Wang, Q. M., Zheng, J. J., Xu, L., Holmes, E. C., \& Zhang, Y. Z. (2020a). A new coronavirus associated with human respiratory disease in China. Nature, 579(7798), 265-269. doi.org/10.1038/s41586-020-2008-3

Wu, Zhiyong, Hu, R., Zhang, C., Ren, W., Yu, A., \& Zhou, X. (2020b). Elevation of plasma angiotensin II level is a potential pathogenesis for the critically ill COVID-19 patients. Critical Care, 24(1). doi.org/10.1186/s13054-020-03015-0

Wu, Q., Zhou, L., Sun, X., Yan, Z., Hu, C., Wu, J., Xu, L., Li, X., Liu, H., Yin, P., Li, K., Zhao, J., Li, Y., Wang, X., Li, Y., Zhang, Q., Xu, G., \& Chen, H. (2017). Altered Lipid Metabolism in Recovered SARS Patients Twelve Years after Infection. Scientific Reports, 7(1). doi.org/10.1038/s41598-017-09536-Z

Wu, Z., \& McGoogan, J. M. (2020). Characteristics of and Important Lessons from the Coronavirus Disease 2019 (COVID-19) Outbreak in China: Summary of a Report of 72314 Cases from the Chinese Center for Disease Control and Prevention. In JAMA - Journal of the American Medical Association (Vol. 323, Issue 13, pp, 1239-1242). American Medical Association. doi.org/10.1001/jama.2020.2648

Xu, Z., Shi, L., Wang, Y., Zhang, J., Huang, L., Zhang, C., Liu, S., Zhao, P., Liu, H., Zhu, L., Tai, Y., Bai, C., Gao, T., Song, J., Xia, P., Dong, J., Zhao, J., \& Wang, F. S. (2020). Pathological findings of COVID19 associated with acute respiratory distress syndrome. The Lancet Respiratory Medicine, 8(4), 420-422. doi.org/10.1016/S2213-2600(20)30076-X
Zhang, C., Wu, Z., Li, J. W., Zhao, H., \& Wang, G. Q. (2020). Cytokine release syndrome in severe COVID-19: interleukin-6 receptor antagonist tocilizumab may be the key to reduce mortality. International Journal of Antimicrobial Agents, 55(5), 105954. doi.org/10.1016/j.ijantimicag.2020.105954

Zhong, J., Basu, R., Guo, D., Chow, F. L., Byrns, S., Schuster, M., Loibner, H., Wang, X. H., Penninger, J. M., Kassiri, Z., \& Oudit, G. Y. (2010). Angiotensin-converting enzyme 2 suppresses pathological hypertrophy, myocardial fibrosis and cardiac dysfunction. Circulation, 122(7), 717-728. doi.org/10.1161/CIRCULATIONAHA.110.955369

Zhou, F., Yu, T., Du, R., Fan, G., Liu, Y., Liu, Z., Xiang, J., Wang, Y., Song, B., Gu, X., Guan, L., Wei, Y., Li, H., Wu, X., Xu, J., Tu, S., Zhang, Y., Chen, H., \& Cao, B. (2020). Clinical course and risk factors for mortality of adult inpatients with COVID-19 in Wuhan, China: A retrospective cohort study. The Lancet, 395(10229), 1054-1062. doi.org/10.1016/S0140-6736(20)30566-3

Zhou, P., Yang, X. Lou, Wang, X. G., Hu, B., Zhang, L., Zhang, W., Si, H. R., Zhu, Y., Li, B., Huang, C. L., Chen, H. D., Chen, J., Luo, Y., Guo, H., Jiang, R. Di, Liu, M. Q., Chen, Y., Shen, X. R., Wang, X., ... Shi, Z. L. (2020). A pneumonia outbreak associated with a new coronavirus of probable bat origin. Nature, 579(7798), 270-273. doi.org/10.1038/s41586-020-2012-7

Zhu, N., Zhang, D., Wang, W., Li, X., Yang, B., Song, J., Zhao, X., Huang, B., Shi, W., Lu, R., Niu, P., Zhan, F., Ma, X., Wang, D., Xu, W., Wu, G., Gasso, G. F., \& Tan, W. (2020). A novel coronavirus from patients with pneumonia in China, 2019. New England Journal of Medicine, 382(8), 727-733. doi.org/10.1056/NEJMoa2001017

Zou, F., Qian, Z., Wang, Y., Zhao, Y., \& Bai, J. (2020). Cardiac Injury and COVID-19: A Systematic Review and Meta-analysis. CJC Open, 2(5), 386-394. doi.org/10.1016/j.cjco.2020.06.010 